\title{
FINITE ELEMENT ANALYSIS OF STATIC WING BOX TEST RIG
}

\author{
Sathish A. S ${ }^{1}$, Sanjay.S.J ${ }^{2}$, V.B.Math ${ }^{3}$ \\ ${ }^{1}$ P.G Student, Mechanical Engineering Department, Basaveshwar Engineering College, Bagalkot, India \\ ${ }^{2}$ Assistant Professor, Mechanical Engineering Department, Basaveshwar Engineering College, Bagalkot, India \\ ${ }^{3}$ Professor, Mechanical Engineering Department, Basaveshwar Engineering College, Bagalkot, India
}

\begin{abstract}
The design of airplane, when plane is in the flight mode it is because of wings on both sides. While operating at the greater speed the wings are subjected to load which includes whole weight of the aircraft and environmental weather conditions. But also during flying the wings are subjected to much higher loads and stress. This stress should be sustained by the wings as per the limit load without causing any permanent deformation to the structure. In order to find how much the stress the wings are subjected to, the procedure for the testing wings on the ground which is called as static test. Static test are carried on the test rig. Wings are mounted on this test rig to analyze the stresses. However these test rigs should be much stronger than the object to be tested on it. In this paper the design parameter such as design configuration given more importance in the development of the test rig. A finite element analysis was done on the model of the test rig to verify the parametric design. So by using ANSYS workbench analysis was performed. There is much deformation in the test rig. By making a suitable alteration on the existing model of the test rig the deformation can be minimized to a small value. Alteration was made to compare if the initial design was good or can be made better.
\end{abstract}

Keywords: Design, Static test, Wing box, Test rig, FEA.

\section{INTRODUCTION}

In the aircraft wing design is constantly evolving. If you were to compare the wing of the Wright Flyer with that of a modern aircraft, such as the Boeing 787, the difference is remarkable. The number of lifting surfaces, shape, size and materials used all contribute to an aircraft's performance. Some of the design parameters are required in order to develop a test rig for a wing box static test experiment. In the aircraft development all structural components in the aircraft must be tested to ensure safety of the aircraft in operation [1]. Structural components of the aircraft must be tested physically to produce an accurate data in line with the theoretical or numerical analysis $[1,2]$ and the experiment should be conducted according to the actual size of the component to be tested for the developed test rig $[2,3]$. If the actual size of the components to be tested, at least a main structural components deemed critical in the actual aircraft can be tested [4]. The developed test rig must be able to withstand a multiple amount of loads compared to the maximum possible the aircraft will endure in real situation [1], thus a strength analysis must be conducted accordingly. It is obvious that only specific wing design should be tested on a specific test rig $[5,6]$. The test rig designing will be done according to the available wing in the faculty of mechanical engineering, UiTm shah Alam which is a light seater cesna 150 airplane wing. Analysis was carried out on a 2D model before an actual design was to be fabricated. After the first design of the test rig an alteration or modification of the design configuration of the test rig are carried out to improve the results. Ramzyzan Ramly et.,al. [10] conducted a design and analysis for development of a wing box static test rig. In his paper he performed only one alteration, but in the present paper we conducted the analysis on one more modification to achieve better results.

\section{METHODOLOGY}

\subsection{Model Description}

The static wing box test rig model having dimensions as, $5 \mathrm{~m}$ in length, $2 \mathrm{~m}$ in width and $2 \mathrm{~m}$ in height. Model was created using the modeling software. Analysis is carried out on the model by using ANSYS Workbench. The basic model through which the desired model being developed is as shown in figure1

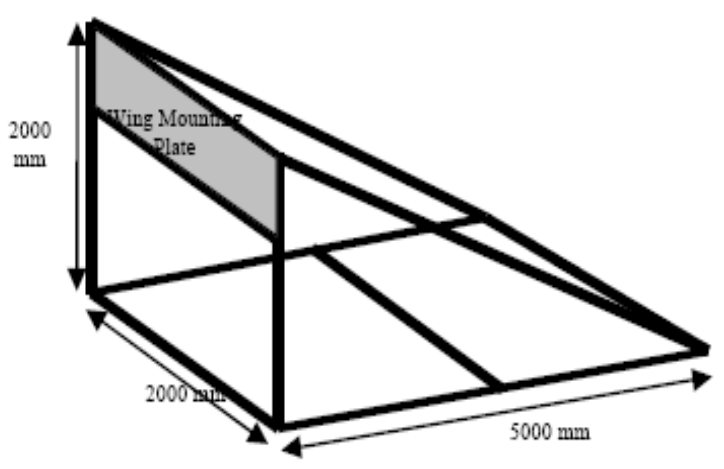

Fig 1: Basic design and dimension of the wing box test rig. 


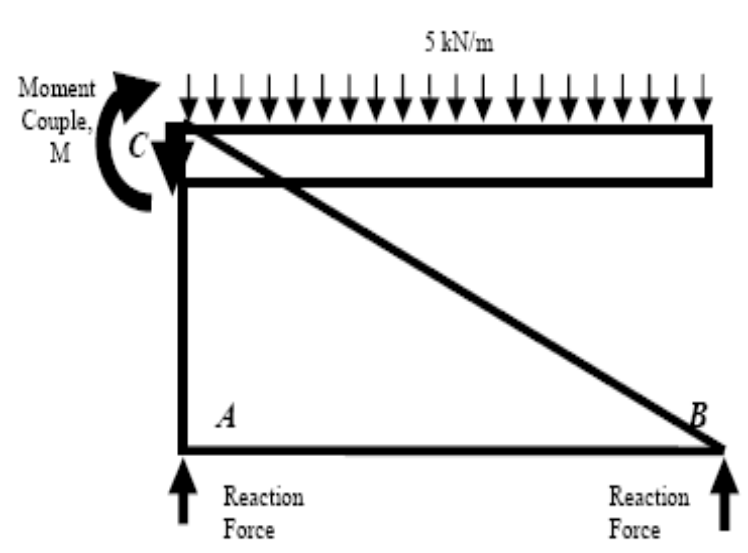

Figure 2: The force diagram of the test rig with wing loading being exerted on the mounting plate.

For the analysis purpose we consider only the side structure model from the above $3 \mathrm{~d}$ model. The side structured model along with the loading condition as shown on figure2. In the figure 2 the test rig designed to carry a load of around $5000 \mathrm{~kg}$ equivalent to light weight aircraft which is around $50 \mathrm{kN}$. Also in figure2 the test rig subjected to half wing load. Since the uniformly distributed load of $5 \mathrm{kN} / \mathrm{m}$ is considered over the $10 \mathrm{~m}$ span of the wing.

Load analysis performed in order to find the internal loads on the test rig and tabulated as shown in table 1.

Table 1: Load properties of the test rig members.

\begin{tabular}{|l|l|l|}
\hline Members & Internal Load & $\begin{array}{l}\text { Load Required } \\
\text { (with F.S. of } \\
\text { 1.5) }\end{array}$ \\
\hline Horizontal AB & $31.25 \mathrm{kN}$ (Tension) & $46.88 \mathrm{kN}$ \\
\hline Vertical AC & $33.65 \mathrm{kN}$ (Tension) & $50.475 \mathrm{kN}$ \\
\hline Diagonal CB & $\begin{array}{l}12.5 \\
\text { (Compression) }\end{array}$ & $18.75 \mathrm{kN}$ \\
\hline
\end{tabular}

For the modeling of the side structure the hallow rectangular section is considered and as shown in figure 3. Rectangular hallow section has the advantage of being stronger in bending. The dimension of the rectangular hallow section is shown in figure 3 below.

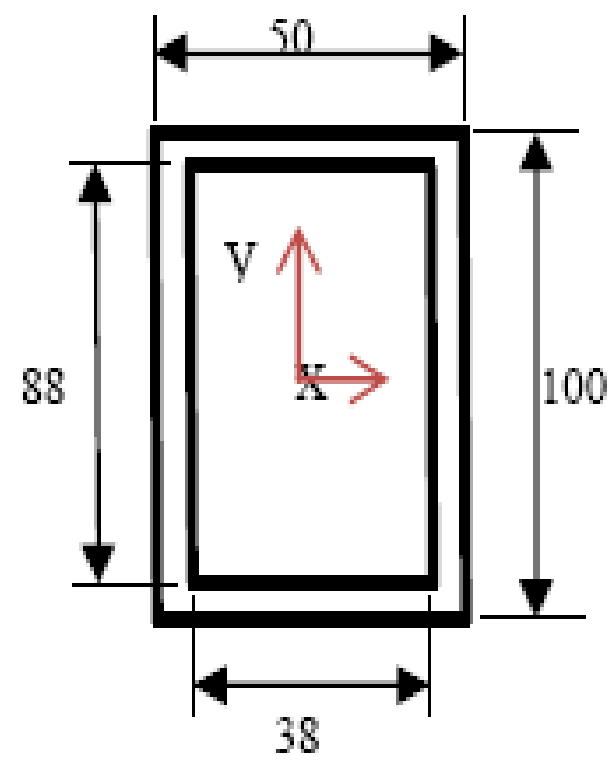

Fig 3: The cross-section of the rectangular beam being proposed.

\section{MODELING AND FINITE ELEMENT ANALYSIS.}

From the modeling software, the model of the static wing box test rig was developed with the actual dimensions as shown in figure 4. By using the ANSYS workbench, analysis conducted on the developed model of the test rig. The model was meshed and the necessary loading boundary conditions are applied as shown in figure 5 . The load of $125 \mathrm{kN}$ was applied at the point $\mathrm{C}$ and $500 \mathrm{~mm}$ below the point $\mathrm{C}$.

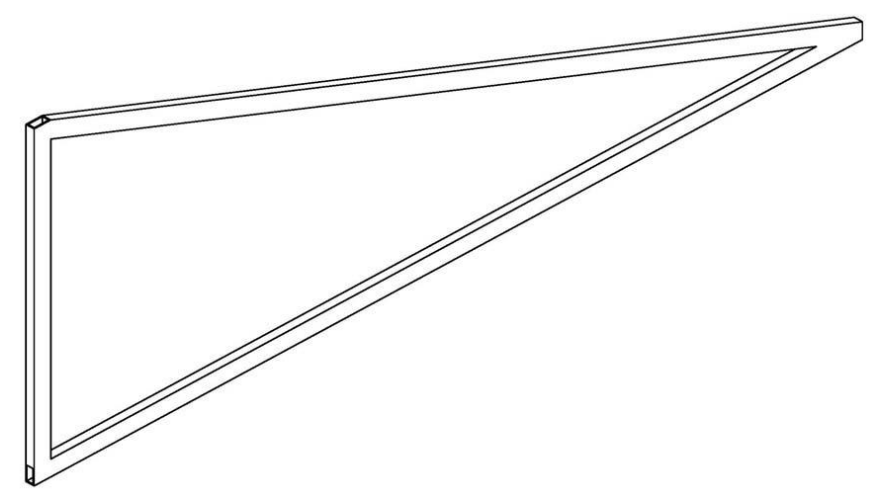

Fig 4: Isometric view of the model for the test rig. 


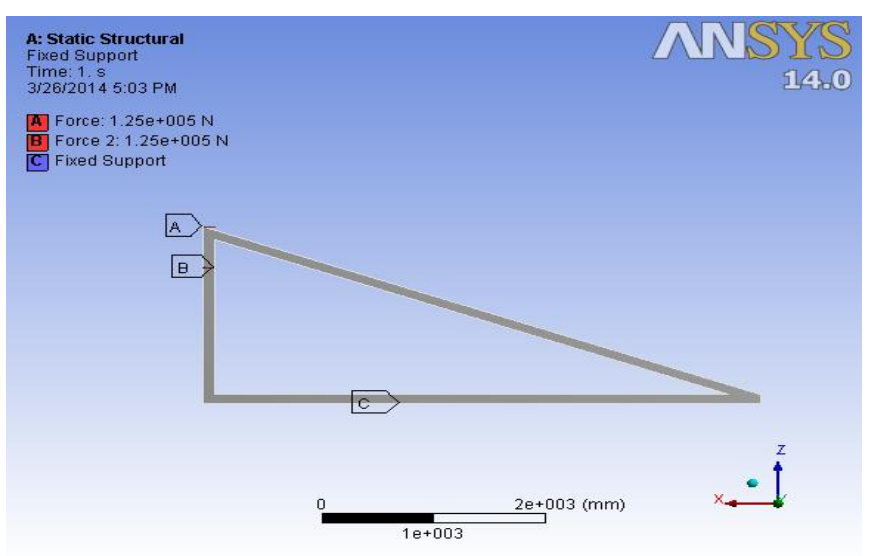

Fig 5: Finite element model of the $2 \mathrm{D}$ side structure of the test rig.

From the above figure 6 showing the deformation of test rig. Since the maximum deflection occurs somewhere at the middle of the AC. The maximum deflection obtained is $0.0008 \mathrm{~m}$ or $0.8 \mathrm{~mm}$. Since according to the ideal design criteria the deflection should not be more than $1 \mathrm{~mm}$.

It is possible to reduce the deflection on the vertical component AC by making some modification in the design configuration of the wing box test rig. The modification is

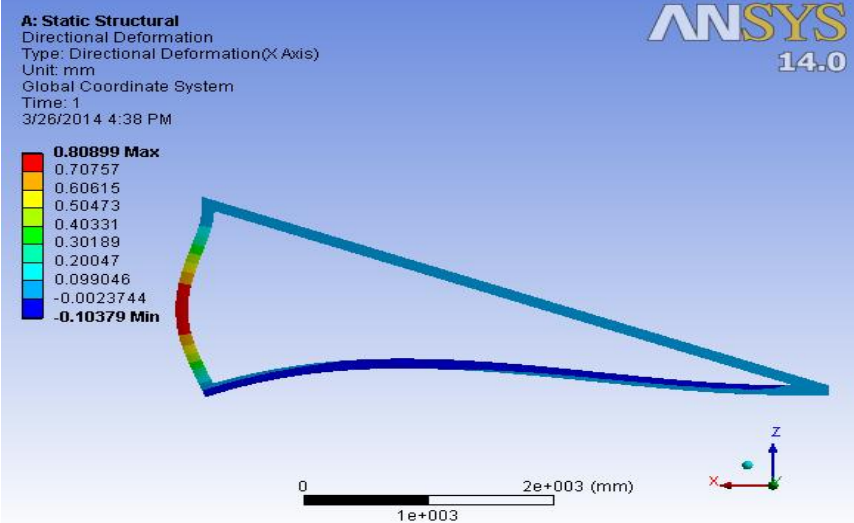

Fig 6: Deformation distribution in $\mathrm{x}$ direction.

done by adding a strut member running from the middle of the component AC to the middle of component CB. Another strut was added vertically from the middle of component $\mathrm{CB}$ to the middle of the component AB. This modification is as shown in figure 7. Again by using CATIA the altered model was developed. The analysis carried out on the altered model using ANSYS workbench, the deformed results as shown in figure 9 .

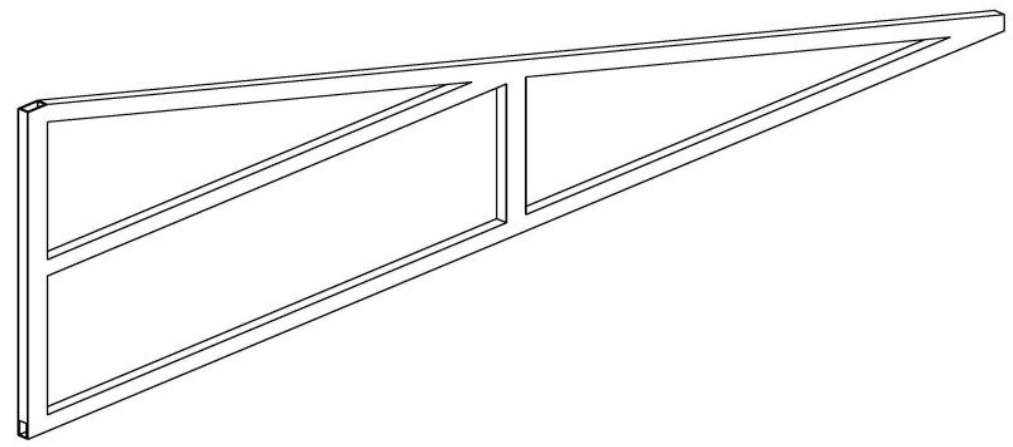

Fig 7: CATIA model of design alteration of the side structure of the test rig.

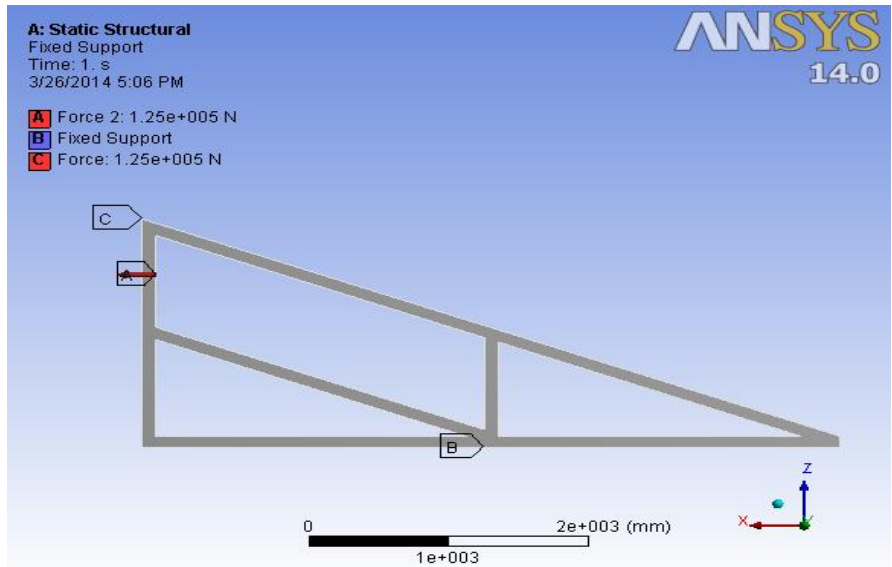

Fig 8: Altered model of the side structure of the altered test rig.

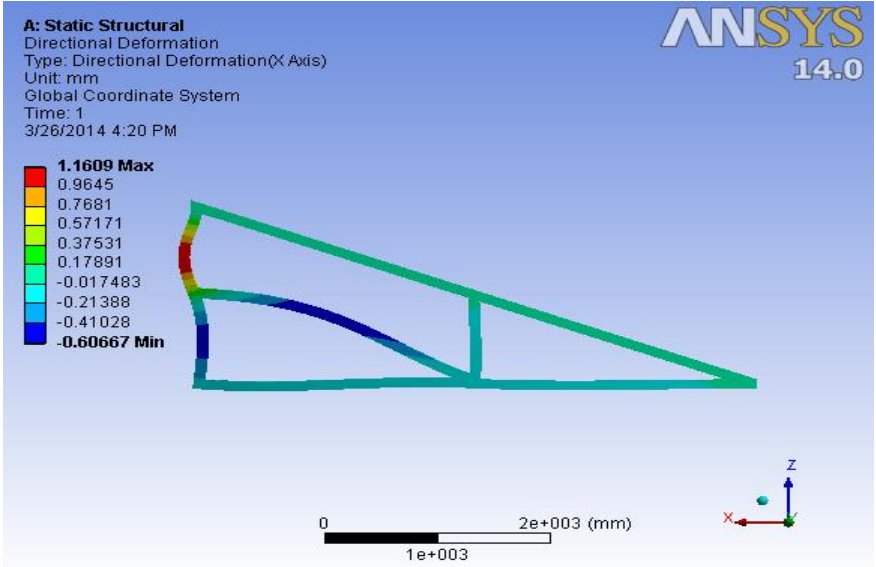

Fig 9: Deformation distribution in $x$ direction of the altered design. 
The obtained results of the model in the above figure 9 having the maximum deflection of $0.0016 \mathrm{~m}$ or $1.6 \mathrm{~mm}$. However at the point $\mathrm{C}$ the deflection ranges between, $0.4 \mathrm{~mm}$ and $0.6 \mathrm{~mm}$ which is consider very low compared to the applied load for the factor of safety of 2.5 .

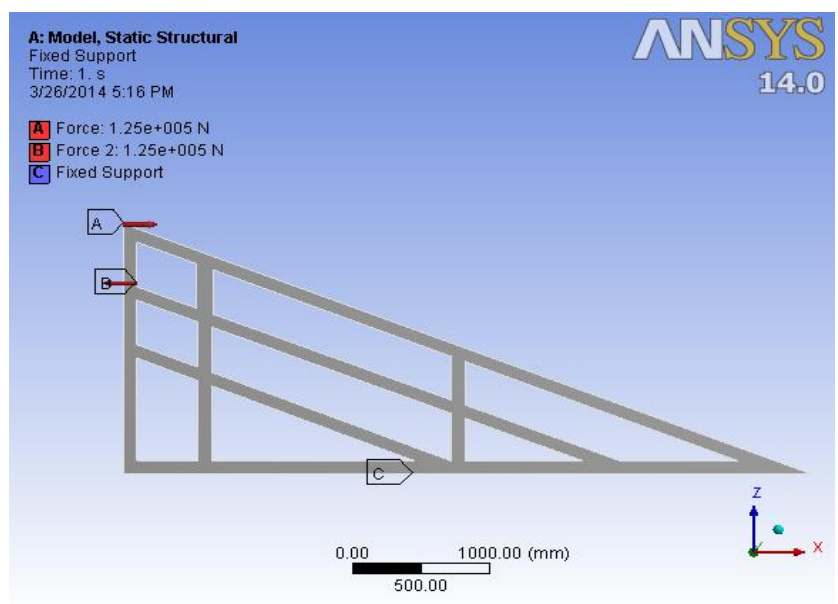

Fig 10: Altered model of the side structure of the altered test rig

\section{CONCLUSIONS}

The design configuration of the static wing box test rig done by using finite element analysis and the design modified frequently to achieve the acceptable design criteria. Desired results can be obtained in less time and the alteration can be done quickly with the available modeling software's. Initially the deflection obtained is $0.8 \mathrm{~mm}$ but after an alteration the deflection was reduced to $0.6 \mathrm{~mm}$. In the final alteration the deflection found to be $0.53 \mathrm{~mm}$ which shows that with changing in design configuration of test rig the more strength can be obtained in the test rig.

\section{REFERENCES}

[1]. Schuster, S. A., (February 1996). Testing the structural Integrity of Boeing 777, Sensors Magazine

[2]. Harrison, S. and Harris, M. Is operational Test and Evaluation Relevant to the Defence Science \& Technology Organization's Aircraft Structural Test Laboratory, System Engineering/ Test and Evaluation (SETE 2003), Canberra, Australia 2003.

[3]. Fugerson, R. Large Scale Composite testing at Airbus Filton Site, 2nd International Conference on Composite Testing and Model Identification, Comptest 2004, Bristol, UK 2004.

[4]. Clarke, A., et al., Structural Analysis and Optimization of an All Composite Damage Tolerant Wing box, Technical Report based on the paper presented at First European
Further it is also possible to reduce the deflection in vertical component by again adding a another strut parallel to previous way in the same manner. The resulting altered test rig model as shown in figure, 10. Analysis shows the overall maximum deflection can be reduced to $0.53 \mathrm{~mm}$ as shown in figure 11 .

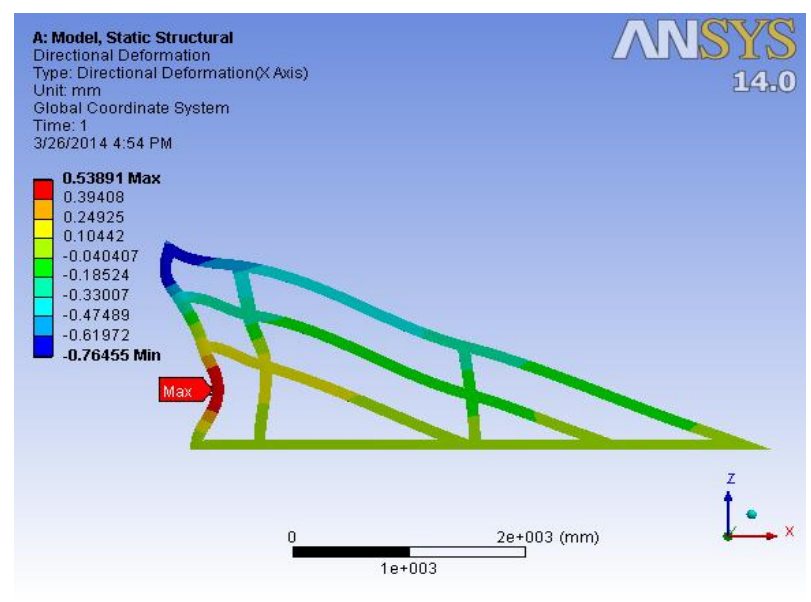

Fig 11: Deformation distribution in $x$ direction of the altered design.

Conference for Aero-Space Sciences (EUCASS), Moscow, July $4-7,2005$.

[5]. Parish, H. E., Fatigue Test Results and Analysis of 42 Piston Provost Wings. Technical Report for Ministry of Technology, Aeronautical Research Council, R. \& M. No. 3474, London 1967

[6]. Hibbler, R. J., Mechanics of Material, 6th ed. SI Units, Pearson Prentice Hall, Singapore 2004.

[7]. A. Gatto, F. Mattioni and M. I. Friswell, Experimental Investigation of Bistable Winglets to Enhance Wing Lift Takeoff Capability, Journal of Aircraft Vol. 46, No. 2, MarchApril 2009.

[8]. U.K. Saha, M. Mitra, S. J. Menon, N. T. John, S. S. Gajapathi, P. Behera, Preliminary design analysis of a lightweight combat aircraft, Proceedings of the Institution of Mechanical Engineers, Part G: Journal of Aerospace Engineering, Professional Engineering Publishing, Volume 222, Number 4 / 2008, 507- 513.

[9]. S. K. Panigrahi and B. Pradhan, Development of Load Coupler Profiles of Spar Wingskin Joints with Improved Performance for Integral Structural Construction of Aircraft Wings, Journal of Reinforced Plastics and Composites 2009; 28:657. 116.

[10]. Ramly et al., Design and analysis for development of a wing box static test rig, Science and Social Research (CSSR), 2010 International Conference on 2010, IEEE. 